\title{
A importância da legitimação social na (re)construção da identidade de um alcoolista
}

\author{
The importance of social legitimization on the \\ (re)construction of an alcoholic's identity
}

\author{
Geraldo Mendes de CAMPOS $^{1,2}$ \\ Ricardo Franklin FERREIRA ${ }^{3}$
}

\begin{abstract}
Resumo
Este artigo busca compreender as dificuldades que um alcoolista encontra, mesmo estando abstêmio, para reconstruir sua identidade a partir de suas interações sociais. Para isso, foram utilizados conceitos de representações sociais e de identidade, da Psicologia Social. O sujeito deste estudo encontrava-se em tratamento ambulatorial em uma unidade de atendimento e pesquisa de uma universidade pública da cidade de São Paulo e vivenciava vários processos de recaída. Sua história de vida foi analisada a partir de entrevista, visando identificar processos sociais que influenciaram a formação de sua identidade. Os resultados apontam a importância do grupo social na indução do retorno ao comportamento aditivo, mesmo que de forma involuntária, dificultando sua emancipação pessoal e induzindo-o à reprodução de seu padrão aditivo. Uma melhor compreensão dessa dinâmica identitária poderá minimizar um problema crônico na recuperação dos dependentes químicos: a recaída.
\end{abstract}

Unitermos: alcoolismo; família; identidade social; legitimação social; psicologia social.

\begin{abstract}
This paper intends to understand the difficulties faced by an alcoholic, even in abstinence, to reconstruct his identity from his social relationships. For such purpose, concepts of social representations and identity, both borrowed from Social Psychology, have been used. The collaborator of this study was a patient undergoing treatment from the attendance and research unity of a public university in São Paulo, who had been experienced various relapsing processes. His life history has been analyzed based on interviews, in order to identify social processes that play a role on the construction of his identity. The results point out the importance of the social group in inducting the addiction behavior back, even if it is involuntary, creating difficulties for the personal emancipation. A better apprehension about this identity dynamics might help to diminish this drug dependents' chronic problem of the rehabilitation process: relapsing.

Uniterms: alcoholism; family; social identity; social legitimization; social psychology.

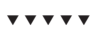

1 Universidade São Marcos, Curso de Psicologia. São Paulo, SP, Brasil.

2 Universidade Federal de São Paulo, Unidade de Pesquisa em Álcool e Drogas. São Paulo, SP, Brasil.

3 Universidade São Marcos, Programa de Pós-Graduação em Psicologia. Rua Clóvis Bueno de Azevedo, 176, Ipiranga, 04266-040, São Paulo, SP, Brasil. Correspondência para/Correspondence to: R.F. FERREIRA.E-mails: <ricardo_franklin@uol.com.br> ou <ricardo@smarcos.br>.

Agradecimentos: À Coordenadoria de Pesquisa da Universidade São Marcos, pelo incentivo à realização da pesquisa que originou este artigo; aos Drs. Ronaldo Laranjeira e Neliana Buzi Figlie, coordenador geral e coordenadora do ambulatório de álcool da UNIAD/UNIFESP, por nos abrirem as portas da Instituição e pelas orientações e ensinamentos ligados à Dependência Química.
\end{abstract}


O alcoolismo tem se mostrado, na atualidade, um dos fatores que agravam vários problemas sociais, econômicos e de saúde (Edwards, Marshall \& Cook, 1999).

Um estudo epidemiológico de Carlini, Galduróz, Noto e Nappo (2002) estimou em 11,2\% da população, cerca de cinco milhões de pessoas, os dependentes de álcool, em 2001, no Brasil. O sexo masculino apresentava uma porcentagem maior quanto à dependência de álcool, para todas as faixas etárias estudadas.

No Estado de São Paulo, outro estudo realizado pelo Centro de Informações sobre Drogas Psicotrópicas (CEBRID) (Galduróz, Noto, Nappo \& Carlini, 2000), em 24 de suas maiores cidades, identificou que cerca de $6,6 \%$ da população era dependente de álcool. O preocupante é que, dois anos depois, houve um aumento da incidência do alcoolismo na mesma população pesquisada, conforme artigo de Galduróz e Caetano (2004), constatando-se um aumento significativo para 9,4\% de dependentes. Esse mesmo estudo aponta um fato inquietante: no Brasil, 5,2\% dos adolescentes (de 12 a 17 anos) já são dependentes e há uma tendência de aumento dessa porcentagem.

Para Pechansky, Szobot e Scivoletto (2004), o álcool já é a substância mais consumida pelos jovens, havendo uma diminuição gradual da idade em que o adolescente inicia seu uso, o que, por sua vez, está associado ao baixo desempenho escolar, ao aumento de comportamentos de risco e prejuízo em seu desenvolvimento cognitivo e emocional. Para se ter a dimensão do problema, um estudo realizado com alunos do ensino fundamental e médio da rede pública, em dez capitais brasileiras, aponta para um consumo de álcool por 65 a 80,8\% dessa população; e entre as crianças de 10 a 12 anos, 51,2\% já fizeram uso dessa substância (Galduróz, Noto \& Carlini, 1997). Já Micheli e Formigoni (2001), comparando três grupos de jovens (sem dependência, dependência leve ou moderada e dependência grave), em São Paulo (SP), encontraram idades médias de início de consumo de álcool aos 13, 12 e 9 anos, respectivamente, com casos em que esse início deu-se aos cinco anos de idade.

Se, por um lado, a criança brasileira está começando a beber mais cedo, por outro lado esse consumo vem se prolongando até mais tarde, na terceira idade. Constatou-se que 15,1\% dos idosos que procuraram das Clínicas da Faculdade de Medicina da Universidade de São Paulo tinham prevalência de alcoolismo (Hirata, Almeida, Funari \& Klein, 1997).

A Medicina, principalmente a Psiquiatria, já conta com conhecimentos acerca das alterações causadas pelo consumo de álcool e outras substâncias psicotrópicas no sistema nervoso central, bem como a farmacoterapia necessária para reequilibrá-lo, como mostram os estudos de Almeida, Dractu e Laranjeira (1996); Ramos e Bertolete (1997); Laranjeira, Nicastri, Jeronimo e Marques (2000); Focchi, Leite, Laranjeira e Andrade (2001); Laranjeira e Pinsky (2001); Baltieri (2004), dentre outros.

A Psicologia, por sua vez, vem desenvolvendo ações terapêuticas eficazes no combate à dependência química, atuando no comportamento, na cognição ou na compreensão da personalidade do drogadito, como mostram os trabalhos de Marlatte Gordon (1993); Silveira Filho (1995); Edwards e Dare (1997); Edwards et al. (1999); Marlatt (1999); Becke Wright (2001); Miller e Rollnick (2001); dentre outros.

Outros estudos buscam compreender as variáveis associadas à reversão do alcoolismo que permeiam as atividades de grupos de ajuda-mútua, como os "Alcoólicos Anônimos" (Campos, 2004; Rodrigues \& Almeida, 2002).

Já é consenso entre os profissionais que trabaIham na área, a necessidade de ações multidisciplinares para a diminuição do problema das drogas em nosso meio. Como aponta o trabalho de Dalla-Déa, Santos, Itakura e Olic (2004), o psicólogo tem uma função fundamental tanto na prática clínica quanto na prevenção. É comum, hoje, observarmos serviços especializados em que atuam, lado a lado, psiquiatras, clínicos gerais, psicólogos, assistentes sociais, terapeutas ocupacionais, enfermeiros e outros especialistas.

Vários estudos ressaltam a dificuldade de se conseguir a prevenção dos comportamentos aditivos e, principalmente, sua recuperação, em função de muitos alcoolistas terem seus comportamentos aditivos reinstalados após se submeterem a tratamentos (Rigotto \& Gomes, 2002; Vaillant, 1999). Essa dificuldade é que determinou este trabalho. Sentimos a necessidade de compreender algumas variáveis associadas à recaída desses pacientes.

Com ênfase na perspectiva das representações sociais e amparado no conceito de "identidade como 
metamorfose" (Ciampa, 1977, 1990, 1994), este artigo visa compreender as dificuldades que um alcoolista encontra, mesmo estando abstêmio, na "reconstrução" de sua identidade a partir das interações sociais, além de contribuir, também, para a discussão da dependência química a partir de uma perspectiva psicossocial.

Neste trabalho, "representação social" é considerada como a categoria definida por Jodelet (2001, p.22) como "uma forma de conhecimento, socialmente elaborada e partilhada com um objetivo prático, e que contribui para a construção de uma realidade comum a um conjunto social. Igualmente designada como saber de senso comum ou ainda saber ingênuo".

As representações sociais organizam as condutas e participam na construção das identidades pessoais. Para Moscovici (2003), elas estabelecem padrões para objetos e pessoas, transformando-os em determinados tipos que passam a ser partilhados pelas pessoas na construção de suas"realidades".

Autores como Berger e Luckmann (1985) e Ciampa $(1977,1990,1994)$ nos permitem compreender como o indivíduo, em seu modo peculiar de ser e com suas representações constituintes de seu mundo simbólico acerca da realidade, vai se configurando numa relação dialética que se dá entre ele e a sociedade em que se insere, por meio de um processo em que tanto sua subjetividade quanto a sociedade vão se construindo mutuamente.

As representações de mundo e de si mesmo, além de permitirem que o indivíduo desenvolva uma organização pessoal, possibilitam que ele organize sua relação com o mundo físico e social. Tais representações são coletivamente compartilhadas e se articulam com as referências do grupo social maior em que o indivíduo vive. Dentre as referências que constrói acerca do real, está incluída aquela pela qual "ele pode reconhecer-se como um determinado indivíduo - sua identidade" (Ferreira, 2000). Assim, poderíamos considerar que, como pondera Duveen (1998, p.98), a identidade se configura por meio da"entrada do indivíduo no mundo das representações".

Para Ciampa (1990), a identidade pessoal é construída a partir de padrões oferecidos pela estrutura social. Uma vez vinculado a um determinado contexto social, o desenvolvimento da identidade dá-se em uma articulação entre igualdades e diferenças. Tal processo favorece no indivíduo o desenvolvimento de uma conscientização de si por meio de comparações que faz nas relações sociais que mantém.

É interessante a formulação de Ciampa (1990, p.243) acerca da categoria identidade - não é considerada simplesmente como uma representação da pessoa, semelhante a um centro estático e, sim, concebida como um processo de metamorfose constante que "representa a pessoa e a engendra". Esse último aspecto é de grande importância para entendermos as questões apontadas sobre a formação da identidade do alcoolista. A identidade não se reduz somente a uma representação do indivíduo que o distingue de outros e, simultaneamente, indica uma semelhança sua em relação a determinado grupo de referência. É mais do que isso, e o que é crucial, a identidade é uma referência em torno da qual a pessoa se constrói, e a maneira de se construir é que permite que ela se localize em seu mundo com certa segurança. Assim, podemos dizer que o alcoolista se constrói, além de várias outras referências, em torno de seu próprio alcoolismo.

Para Berger e Luckmann (1985), a identidade pode ser entendida como uma intersecção entre a identificação atribuída pelos outros e a auto-identificação apropriada pelo próprio indivíduo, visto que se mantém em curso uma simultaneidade entre a exteriorização do ser na sociedade, a objetivação de uma realidade social e a interiorização dessa realidade pelo indivíduo.

Uma vez em constante processo de construção, qualquer característica da identidade necessita antes estar objetivada e socialmente compartilhada, para depois passar a fazer parte da realidade subjetiva do indivíduo (Ciampa, 1990). Isso significa dizer que um indivíduo não conseguirá mudar a visão de si, se, ao mesmo tempo, os membros de seu grupo social também não o fizerem, legitimando essa nova visão.

A conservação ou transformação da identidade está na dependência das relações sociais objetivas das quais o indivíduo participa. Esse processo se dá principalmente nas conversações, que assumem o papel de principal mediador na mútua construção tanto das subjetividades pessoais quanto da realidade social. Assim, as representações construídas pelo indivíduo acerca de si mesmo serão interiorizadas como integrantes de sua identidade se ultrapassarem os meca- 
nismos das relações sociais objetivas (Berger e Luckmann, 1985).

Nesse ponto, é importante ressaltar como entendemos o processo de interiorização proposto por esses autores, o que foi discutido em maior profundidade no artigo de Mattos, Castanho e Ferreira (2003). A interiorização, aqui, não é entendida como um processo que se dá por meio de uma coerção social, como uma imposição do outro, determinando que conteúdos veiculados socialmente sejam necessariamente interiorizados pelo indivíduo. Para Oliveira (1993, p.38), a internalização de representações fornecidas pela cultura não é "um processo de absorção passiva, mas de transformação, de síntese". Assim, as representações interiorizadas pelo indivíduo possuem um significado compartilhado socialmente por pessoas pertencentes a uma mesma cultura; porém, ao se tornarem um processo intrapsíquico, essas representações sofrem uma síntese que se articula com o"sentido" pessoal que o indivíduo atribui àqueles conteúdos socialmente veiculados. Dessa forma, o processo de interiorização é "permeado por uma ressignificação individual que metamorfoseia o conteúdo compartilhado, adquirindo um sentido intrapsíquico singular" (Mattos et al., 2003, p.126).

Assim, a reconstrução de uma identidade já estabelecida - no nosso caso de uma identidade de alcoolista, para uma identidade estabelecida de abstêmio - necessita um compartilhamento e legitimação social dessa nova atribuição; ou seja, a concepção que o indivíduo possui de quem realmente acredita ser somente poderá mudar se, de alguma forma, for confirmada pelos outros. As pessoas significativas para o indivíduo, conforme Berger e Luckmann (1985), é que darão condições de plausibilidade para essa nova identidade.

Podemos, então, dizer que o alcoolista - assim como qualquer pessoa - se constrói e se organiza em seu mundo por meio da relação que estabelece com as pessoas significativas do grupo social do qual faz parte. De um lado, ele constrói sua maneira de existir como alcoolista a partir de representações pertencentes à estrutura social na qual se insere (e não podemos nos esquecer que se trata de uma sociedade em que o álcool, considerado uma droga lícita, é valorizado por meio da mídia e dos costumes) e, de outro, age sobre a mesma sociedade de forma contínua e dinâmica a partir de sua identidade de alcoólico, numa relação de mútua construção.

Nesse aspecto, a visão pejorativa de si mesmo, construída e internalizada em relações sociais estigmatizadoras, pode levar o alcoolista a manter sua condição de dependente químico, determinando, em muitos casos, a não adesão ao tratamento e sucessivas recaídas.

Assim, um alcoolista poderá ser encarado, dependendo de seu meio social, como um doente ou como um indivíduo com desvio de caráter, concepções muito comuns em nossa sociedade. Seja de qual maneira for, o estigma estará presente. Nesse contexto, por um lado, será visto pelos outros a partir desse atributo pejorativo socialmente compartilhado e, por outro lado, o indivíduo alimentará esse atributo à medida que reproduz os comportamentos a ele associados. Dessa forma, dificilmente terá como reconstruir essa identidade atribuída e por ele reproduzida.

A utilização do termo estigma nos remete à obra de Goffman (1963). Nessa visão, o indivíduo passa a ser apreendido principalmente a partir da personagem de alcoolista. Como entendemos, baseados em Ciampa (1990), que a identidade concretamente se expressa por meio de uma articulação de vários personagens, é importante especificar que os outros personagens que o indivíduo poderia expressar acabam ficando solapados por uma apreensão superdirecionada ao personagem de alcoolista. Assim, pode haver então uma identificação muito intensa do indivíduo com as tipificações que Ihes são socialmente atribuídas e as quais ele reproduz. Ele se vê como "não sendo nada senão esse tipo" (Berger \& Luckmann, 1985, p.125). Em suma, ele será visto pelos outros a partir do atributo pejorativo, além de os outros atributos pelos quais poderia ser reconhecido serem minimizados pela supremacia da apreensão dele como um "tipo alcoolista". Além disso, o próprio indivíduo tenderá a reproduzir o "tipo alcoolista" por ele interiorizado, alimentando o estigma que lhe é atribuído pelos outros significativos, num processo constante de retroalimentação. Trata-se, portanto, de um verdadeiro processo de co-dependência em torno do alcoolismo, entre o indivíduo drogadito e as pessoas mais próximas, como parentes e amigos. 
Assim, o indivíduo, involuntariamente, tende a interiorizar, dando um significado próprio, aquilo que Ihe éatribuído e se submete a um processo de reposição, uma reatualização de uma identidade pressuposta socialmente. Isso criará dificuldades imensas para possíveis transformações, permanecendo preso a uma 'mesmice imposta' (Ciampa, 1990), reproduzindo sua identidade de alcoolista. Ao buscar reverter sua condição, não bastará, em abstinência, reconhecer sua'nova'identidade, que, se não for socialmente aceita e reconhecida pelo seu meio, parecerá fictícia e falsa até para ele mesmo. Essa identidade reconstruída necessitará da legitimação social para que seja por ele considerada verdadeira e interiorizada.

Os processos descritos até aqui nos sugerem que a mudança de uma posição de alcoolista para uma situação de abstêmio seja um processo semelhante à conversão religiosa, em que há transformações drásticas de identidade. É um processo que requer uma nova ressocialização do indivíduo e muito difícil de se dar. Berger e Luckmann (1985) denominam esse tipo de mudança de alternação. Trata-se de um processo semelhante à socialização primária, que ocorre na primeira infância, por meio da qual a criança aprende a ser um membro do grupo social ao qual pertence. Nesse processo, a criança interioriza a realidade social, com suas regras e significados, passa a compreender o mundo em que vive e esse mundo passa a ser o seu próprio mundo.

Para Berger e Luckmann (1985), no processo de alternação, deve ser reproduzida em grau considerável a "identificação fortemente afetiva com o pessoal socializante" (p. 208). Assim, nesse processo, o indivíduo tem que enfrentar o problema de desmantelar a precedente estrutura de seu mundo simbólico, por meio do qual dava sentido a si e a seu mundo. Para os autores, a condição mais importante para que isso ocorra é a possibilidade do indivíduo dispor de uma base social que the sirva de 'laboratório' para sua transformação. Essa base social, de pessoas significativas com as quais deve estabelecer forte identificação afetiva, é que lhe poderá oferecer uma estrutura de plausibilidade para uma transformação efetiva.

Acreditamos que um dos principais fatores que levam um alcoolista à recaída pós-tratamento seja a dificuldade de re-construção de sua identidade, pois encontra-se desamparado, em um lugar social que the é imputado nas relações sociais, em que Ihe são atribuídos apenas padrões que o consideram doente, incapaz, improdutivo, não confiável, sem caráter, e tantos outros adjetivos pejorativos. E as recaídas intermitentes acabam "confirmando" esses padrões a ele atribuídos. Tais circunstâncias podem impedir o processo de alternação. A história de José poderá nos dar elementos para compreendermos esses processos e algumas condições que dificultaram sua recuperação.

\section{Método}

Esse trabalho utilizou como técnica de pesquisa a história de vida, que pode ser entendida, de um modo geral, como o levantamento da narrativa de uma experiência biográfica, informada pelo próprio autor, e que visa compreender suas relações sociais, sua visão de mundo e como interpreta sua situação de vida (Becker, 1999). Consideramos que, nas pesquisas sobre identidade, a história de vida é uma técnica adequada, pois permite identificar a relação dialética entre o indivíduo e seu grupo social (Laville\& Dionne, 1999; Queiroz, 1991).

Foi feito um estudo de caso com um profissional liberal com curso superior, aqui chamado de José, paciente alcoolista com mais de 15 internações, que se encontrava em tratamento ambulatorial para dependência alcoólica em uma unidade de atendimento e pesquisa de uma universidade pública da cidade de São Paulo.

Um dos autores deste trabalho, estagiário em um programa de prevenção ao consumo de álcool e outras drogas em escolas do ensino fundamental, após contatos pessoais com o grupo de pacientes da unidade de atendimento onde trabalha, escolheu José para participar como depoente do estudo, pela facilidade com que expressava suas idéias e pelo grande número de recaídas que já havia vivenciado. A descrição de sua história foi levantada por uma entrevista semi-estruturada e flexível quanto à ordem dos temas abordados, realizada na casa do participante. Teve a duração aproximada de duas horas e foi gravada em áudio. Os temas abordados faziam parte de um roteiro prévio, cujo teor o participante desconhecia. Para a análise dos conteúdos da entrevista, foi feita sua transcrição textual. 
Destaca-se que todas as etapas do trabalho seguiram irrestritamente as diretrizes éticas para pesquisas com seres humanos, conforme a resolução 196/96 do Conselho Nacional de Saúde e ratificada na resolução 016/2000 do Conselho Federal de Psicologia. Tanto o participante quanto o coordenador da unidade ambulatorial à qual José estava associado assinaram o Termo de Consentimento Livre e Esclarecido.

Para a análise dos resultados, mais do que um levantamento exaustivo de agentes favorecedores do alcoolismo e suas conseqüências, procuramos compreender como um indivíduo, inserido em um contexto social específico, informado e ciente de seus problemas passados, presentes e futuros, ainda assim retorne a um comportamento aditivo. Para isso, um caminho que julgamos importante foi o de compreender como um indivíduo se constrói. No nosso caso específico, como um alcoolista, em seu contexto social, constrói sua maneira de ser. Buscamos essa compreensão a partir de uma articulação dos conteúdos transcritos da entrevista principalmente com a categoria identidade e com as concepções de Berger e Luckmann (1985), sobre a construção social da realidade.

\section{Considerações sobre a história de José}

O colaborador da pesquisa que originou este artigo (Campos, 2003) foi denominado apenas por José: ora um "José" único em sua individualidade, ora um "Zé" semelhante a tantos outros. Uma história que ao mesmo tempo em que é única torna-se comum. Singular, sem deixar de ser plural.

Desde a infância de José, a permissão para o consumo de álcool era evidente. Havia um padrão familiar legitimado de consumo de álcool em toda sua socialização primária - fato que ele refere com muita ênfase - e rapidamente interiorizado por ele:

Família de gente [origem estrangeira], aqueles enormes aperitivos, almoços... Etodo mundo come, bebe... Eentrei meio que no costume... participando disso e então já tomava cerveja, já 'tava' participando do aperitivo e tal.

Ao ter como modelo os comportamentos de seus pais e de outros familiares nos rituais do aperitivo de domingo, José passou a considerar o consumo de álcool como uma forma de identificar-se com seu mundo familiar. Berger e Luckmann (1985) afirmam que durante o processo de socialização primária a criança interioriza os papéis e as atitudes das pessoas significativas e os tornam seus. No mesmo processo, assume o mundo deles, não como somente uma das possibilidades de mundo; interioriza "como sendo o mundo, o único mundo existente e concebível" (p.180). Assim, para José, uma maneira de ter um sentido de pertencimento era participar dos aperitivos da família.

É importante ressaltar as relações intersubjetivas entre os atores sociais nas situações concretas em que essas relações se dão e o papel ativo do indivíduo na interiorização de aspectos da realidade social. Apesar de limitado, o mundo das pessoas significativas de José provavelmente apresentava uma multiplicidade de modelos e costumes. Ele poderia ter escolhido a comida ou outras características para se sentir incluído. No caso de José, o modelo de identificação escolhido por ele, ao desenvolver um sentido de pertencimento familiar, foi o de "participar dos aperitivos", dentre outros hábitos de sua família. Como ele mesmo diz: "entrei meio que no costume". É possível que essa escolha tenha se dado como uma estratégia para se relacionar socialmente, pois, como ele diz: "eu era um cara extremamente tímido. Eu descobri no álcool uma libertação".

Por volta de seus 14 ou 15 anos, José passou a beber não só na família como também com seus amigos. Isso se deu numa idade em que muitos jovens passam a consumir álcool, como apontam Micheli e Formigoni (2001). Nessa fase, os adolescentes formam sua nova estrutura psicológica modificando e atualizando as várias identificações originárias dos modelos parentais presentes em suas vidas (Moraes \& Figlie, 2004). Como seu modelo pregresso já incluía o consumo de álcool, modificar seu hábito de beber em família para beber com os amigos foi um desdobramento fácil.

A relação de José com o álcool se agravou quando concluiu o ensino médio e passou a freqüentar um curso preparatório para o vestibular, por dois fatores que ele considera fundamentais: primeiro, por não ter sido aprovado no vestibular na primeira tentativa, o que, além de provocar grande decepção, contradizia tudo o que os outros - e conseqüentemente ele próprio - esperavam dele; depois, por se deparar com toda a liberdade (conforme suas palavras) propiciada pelo "cursinho" que freqüentou. 
Quanto ao primeiro fator, José tinha como certo ser "intelectualmente superior" e que passar no vestibular seria fácil. Como pondera Ciampa (1990, p.131), nós "interiorizamos aquilo que os outros nos atribuem de tal forma que se torna algo nosso". José absorveu atributos de sucesso ressaltados pela família e amigos, o que favoreceu uma exigência muito grande em relação a si mesmo:

\footnotetext{
... era uma coisa que eu já tinha me acostumado, porque as pessoas, quando se referiam a mim, falavam assim:... porque o José, o Josééum cara inteligente.... Então, parece que eu vinha ouvindo aquilo... eu falei assim: 'é a minha sina, e eu quero isso'... Eu presteivestibular prá... eu 'tava' superestimando minha capacidade... Eu 'tava' achando que euerao melhoraluno.
}

Uma vez posta em dúvida uma identidade construída com aspectos atribuídos socialmente, o indivíduo passa a questionar seu auto-reconhecimento como se ele próprio estivesse enganado sobre si mesmo (Ciampa, 1990). No caso de José, o personagem do 'Zé-intelectualmente-superior', com o qual se identificara durante toda a adolescência, passou a ser questionado. Ao mesmo tempo, o segundo fator - as vivências propiciadas pelo"cursinho"- agravou sua relação com o álcool. Habituado às situações que Ihe eram corriqueiras e seguras, passou por um novo processo de socialização em que se deparou com situações inusitadas que, apesar de lhe proporcionarem uma sensação de autonomia, ao mesmo tempo Ihe causavam estranhamento. Ele se considerava tímido e viu-se exigido a se relacionar com muitas pessoas, situações com as quais sentia muita dificuldade de lidar, buscando no álcool uma estratégia para enfrentá-las:

Quando eu entrei no 'cursinho', descobri um universo totalmente diferente, descobri que a vida existe. Toda aquela liberdade de entrar ou não entrar na sala, de conhecer um monte de gente e tudo... eu adorei aquilo; só que eu não 'tava' preparado prá aquilo; eu não sabia ter aquele convívio social, aquel a coisa que era comum a todo mundo. Esaia à noite direto e tal... então eu descobri no álcool ... bastava beber uma ou duas eu já ... me encaixava na situação.

O "Zé-seguro" foi perturbado pela necessidade de se "encaixar" em um lugar que não era o seu: antes um ambiente escolar que Ihe era familiar, agora um lugar que não conhecia, mas extremamente atraente. Para enfrentá-lo, o "Zé-tímido" renasceu como o "Zé-al- coolizado", que precisava apenas beber uma ou duas doses para se sentir instalado nesse novo universo. Conforme seu relato, ao término das aulas preparatórias para o vestibular, iniciava um consumo de cervejas que se estendia durante toda a tarde, em companhia dos colegas de aulas.

Após um ano de cursinho e a aprovação no vestibular, José passou a freqüentar a universidade. Novas exigências, novas dificuldades. Passou a beber muitas doses diariamente e em vários momentos do dia: logo pela manhã já ingeria duas ou três doses de "pinga com limão"; no intervalo das aulas, mais uma ou duas doses e ao final do período tomava cerveja junto a uma "bebida quente". À noite - e todas as noites - a preferência recaía sobre os destilados (uísque, vodka, conhaque, etc.).

Como a identidade é a articulação de vários personagens (Ciampa, 1990), nessa fase de sua vida, conviviam os personagens 'Zé-alcoolizado', e ainda vestígios do 'Zé-intelectualmente-superior', que se constituíam um em relação ao outro, formando o 'Zé-universitário-confiante'. A partir desse ponto, a confiança dá lugar ao desespero e à frustração. Como ponderam Berger e Luckmann (1985), "são necessários graves choques no curso da vida para desintegrar a maciça realidade interiorizada na primeira infância" (p. 190). Desta feita - e pela primeira vez em seu relato - José abandona uma identidade pressuposta socialmente que vinha sendo constantemente reposta, para finalmente possibilitar-se ser aquilo que se certificara ser: um 'Zé-alcoolista-dependente-químico' que precisava de ajuda.

A dependência química, uma vez constatada, necessita ser assumida, para que se possa combatê-la. Como nos conta José:

Eu demorei pelo menos uns ... oito anos por aí, prá olhar prá mim e um dia, sentar na minha cama, começar a pensar no termo alcoólatra, alcoólatra, alcoólatra... e quebrar aquela resistência. Ecomecei a chorar efalei:não! Eu sou, não adianta, não tem como fugir.

Esconder o problema, embora seja a busca de solução mais corriqueira, não traz nenhum benefício e, embora constrangedor, o assunto precisa ser abordado. Porém, a demora da família e dos amigos de José em aceitarem sua condição de alcoolista foi um dos fatores que possivelmente retardaram sua motivação para enfrentar o problema. 
Meus amigos... desde que eles descobriram que eu era dependente químico... tiveram dificuldade em aceitar isso, que eu era alcoolista. É... todo mundo demora, a gente demora um pouquinho, a família demora um pouco mais, os amigos também. Então, numa determinada época eu cheguei prá eles e contei: não, eu sou alcoólatra e eles falaram assim: não, você deve estar exagerando!

Por nos construirmos no contexto social, a demora em aceitar a dependência química, por parte do grupo social, aponta para uma negação do problema que, conseqüentemente, poderá ocorrer também com o próprio dependente. Uma vez que a estrutura de plausibilidade não reconhece - ou minimiza - a condição de alcoolista apontada por José, então nada precisa ser feito, pois o problema não existe.

Outros fatores que dificultaram a mudança do comportamento aditivo de José foram sua constante presença em festas e o padrão de conduta social das pessoas de seu grupo profissional.

Todo mundo dessa área bebe bastante... todas as festas são regadas a álcool. Depois de anos e anos convivendo com a bebida, teu comportamento tá baseado em algumas doses de álcool. Quando vocêpára, vocêsesente meio estranho nos lugares, você não tem aquela facilidade de contato pessoal, de socialização, de se libertarnuma festa. No meu caso não é só uma coisa que eu quero, mas é uma exigência da minha profissão. Porque se eu ficar quietinho no meu canto, eu não vou conseguir trabalho e nem nada disso.

Nesse grupo, José se via compelido a repor o personagem "Zé-alcoolizado" para não ser tomado por uma sensação de estranhamento; como define Ciampa (1990), uma "mesmice imposta" a que foi levado, a repetir-se como uma réplica de si mesmo. Durante muito tempo José reproduziu esse personagem, em função da dificuldade - mesmo que momentânea - de aceitação do personagem "Zé-alcoolista-dependente-químico".

Algum tempo depois, as constantes intoxicações, internações e recaídas vivenciadas por José fizeram com que sua situação de dependente químico não fosse mais negada. Estava preparado o terreno para que buscasse a abstinência alcoólica: já aceitara sua situação de alcoolista e a família e os amigos já tinham a real dimensão de seu problema com o álcool.

O que faltava então para que José modificasse seu comportamento aditivo e definitivamente superasse o "Zé-drogadito"? Esse personagem, que desta feita já se encontrava cristalizado, só poderia ser modificado por meio das relações sociais. Qualquer transformação na identidade necessita de legitimação pelos grupos sociais dos quais o sujeito participa. Embora José já apresentasse sinais de tentativa de mudança de comportamento, o personagem "Zé-em-recuperação" ainda não estava completamente interiorizado e legitimado pelas pessoas próximas.

José mantinha e reproduzia sua identidade, mesmo com sua intenção de modificá-la, devido ao poder que o personagem "Zé-drogadito" exercia sobre ele, pois a realidade de drogadito já estava interiorizada e persistente, tanto em si, quanto em seu grupo social. O valor afirmado por sua família e amigos, nessa fase, continuava sendo seu comportamento aditivo e não sua luta para modificá-lo:

Minha familia, sempre quando eu volto de uma recaída, as primeiras semanas, os primeiros meses... é uma preocupação no sentido de que eu não recaia, de queeu não tenha contato com álcool, que eu tome a medicação corretamente etal.... Deficar alerta 'pro'meu comportamento ... . Então, vira e mexe, eu 'tô' em abstinência total, mas um dia que eu 'tô' cansado, 'tô' mal humorado, não 'tô' com muita vontade de falar... basta eu mudar meu tom de voz, me mostrar cansado, chateado quejá: 'Tá tudo bem com você?' - 'Tá tudo bem com você?', quer dizer: vocêvoltou a beber?

Como já apontado, o relato de José explicita como o problema de alcoolismo de um membro da família pode provocar co-dependência nas pessoas mais próximas. Essa incessante suspeita por parte dos outros significativos, embora compreensível, alimentava a dependência alcoólica e escancarava a falta de confiança na recuperação de José. Isto nos parece claro, pois todos de seu grupo familiar e de seu grupo de amigos participavam dessa co-dependência. A família e amigos criavam uma situação em que José se sentia tolhido, em função do constante estado de alerta e suspeitas quanto ao seu comportamento em relação à bebida. Isso criava, na sua visão, condições favoráveis, mesmo que involuntárias, para o retorno ao álcool, enquanto um gesto que o fazia sentir-se mais autônomo em relação à expectativa desses outros. Nas suas palavras, uma "manifestação de independência, de liberdade". A atitude dos familiares e amigos, que pretendia ser de proteção, era interpretada por José como interferência negativa em sua vida, mesmo sendo outra a intenção deles. 
Assim, a família e o próprio José criavam uma situação em que ele se sentia limitado em sua liberdade. Esse sentimento o levava a beber, como um ato de auto-afirmação. A família, por medo, procurava exercer algum controle para que a recaída não ocorresse. Por sua vez, isso fazia José se sentir mais limitado, o que acabava por favorecer a recaída. Criava-se, assim, um círculo vicioso e a manutenção da co-dependência. Porém, José tendia a responsabilizar a família, como mostra seu relato:

O voltar a beber, às vezes, pode se dar por uma reação contrária. Não que alguém sugira, que alguém incentive, mas o voltar a beber é uma manifestação de independência, de liberdade. 'Tá'todo mundo à minha volta não querendo que eu beba, 'tá'todo mundo tomando conta de mim. Mas a vidaéminha, eu faço o que queroeeuvou beber. Nas minhas recaídas eu já tomei essa atitude, entendeu? Como que eu querendo dizer: 'olha, familia, vocês me querem muito bem; amigos, vocês gostam muito de mim, mas eu faço o que eu quero com a minha vida e então eu vou voltar a beber.' Então, de uma certa forma, eles atéparticiparam indiretamente dessa decisão.

A realidade tende a se conservar, na maior parte das vezes, por meio de aspectos implícitos da conversação (Berger \& Luckmann, 1985). Esses conteúdos apreendidos por José nas conversas com as pessoas de sua convivência alimentavam o personagem "Zé-drogadito", não favorecendo que ele se modificasse para sua atual situação concreta, a de que estava em recuperação. Como essa nova realidade não era legitimada por seu meio social - e para conservar a confiança de que era na verdade a pessoa que pensava ser - José passou a considerar necessário afastar-se dessa estrutura de relações.

Essa ruptura se faz necessária quando a auto-identificação do indivíduo não é confirmada pelos outros significativos, como forma de romper com a estrutura de plausibilidade que ameaça sua realidade subjetiva (Berger \& Luckmann, 1985). Para José, o meio em que convivia não Ihe possibilitava confirmar sua identidade de alcoolista em recuperação, pois os outros significativos já haviam cristalizado, apenas, a realidade de sua drogadição. A maneira que ele encontrou para não mais permitir que uma mesmice danosa continuasse a lhe ser imposta foi distanciar-se das pessoas de seu meio.
Isso ocasionou, inclusive, a meuver benéfico prámim hoje, uma mudança de comportamento em relação à minha família. Eu estabeleci a distância que eu tenho que ter da minha família... . Até que num determinado momento, depois de muita terapia e tudo, eu descobri que existe uma distância entre eu e meus pais, entre eu e meus amigos... . E eu estabeleci, eu comuniquei a eles essa distância. Não vou permitir que invadam mais a minha privacidade ou da maneira que eles quiserem e com a freqüência que eles quiserem. Chegar o momento efalar assim: 'é... eu quero ajuda das pessoas, eu me sinto bem com a ajuda das pessoas, mas eu tenho que tomar a minha vida nas minhas mãos... tomar conta da tua vida ... estabelecer a distância, direitinho'.

Atualmente, José não mais se conforma com a identidade que lhe é atribuída pelo seu grupo sociofamiliar e sente que uma forma de evitá-la é tomar sob sua responsabilidade a autonomia de que carece, relacionando-se com outros significativos que lhe dêem a estrutura de plausibilidade necessária para que o personagem "Zé-em-recuperação" possa ser legitimado:

Eujá fiz alguns trabalhos, já sei que são trabalhos bons. Já tive, inclusive um retorno disso... em termos de crítica, em termos do gosto das pessoas. Eu dou aula, sou professor ... eu acho que eu sou um professor bem conceituado... meus alunos têm muita confiança em mim, têm muita credibilidade no que eu falo, no que eu faço... a diretoria tem confiança. Então eu não preciso mais me provar daquela maneira. E não posso imaginar que a única maneira de ter sucesso ésendo o máximo dos máximos.

Parece que novos contextos sociais facilitaram para que surgisse o novo personagem "Zé-bem-sucedido", que vê seu trabalho sendo finalmente reconhecido: os colegas e os profissionais da unidade onde faz o tratamento para alcoolismo; a psicoterapia; a diretoria da instituição onde leciona e seu grupo de alunos - sendo que esses últimos não conheceram o "Zé-alcoolista".

José contenta-se com isso, sem necessariamente precisar ser "o melhor entre os melhores". Uma nova estrutura de plausibilidade surgiu, fazendo com que, finalmente, pudessem ser interiorizados atributos de respeito, confiança, credibilidade e competência.

\section{Considerações Finais}

Na busca de compreensão da dinâmica identitária desse alcoolista, a partir de suas interações 
sociais, evidenciaram-se as dificuldades que um dependente químico pode encontrar para modificar uma identidade pressuposta, principalmente por aspectos que lhe são socialmente atribuídos, ou pelo modo que esse os significa.

Dessa forma, esta investigação constatou, além da responsabilidade do próprio indivíduo, a importância do grupo social no retorno do comportamento aditivo, mesmo que de forma involuntária, dificultando o alcance de uma alternação desejada pelo alcoolista na direção de sua autonomia, induzindo-o à reprodução de sua mesmice.

José buscou, como uma saída para seus problemas decorrentes do alcoolismo, a ruptura com um contexto social particular, para que pudesse se identificar como alguém que buscava a abstinência alcoólica e não apenas como um dependente químico com constantes recaídas, como era socialmente esperado. Entretanto, apenas essa ruptura seria suficiente para que Zé se mantivesse abstêmio? Acreditamos que não.

A necessidade de uma estrutura de plausibilidade para confirmar sua identidade reconstruída permanecia. Em nosso entendimento, a busca por outros significativos que pudessem legitimar sua"nova" identidade foi fundamental. A substituição dessa estrutura tornou-se imprescindível nesse processo. Dessa forma, José pôde ver outros de seus atributos serem realçados, que não apenas aqueles atrelados a sua condição de alcoolista.

Percebemos, então, a importância da legitimação social na recuperação do dependente químico: enquanto, inicialmente, um grupo social não conseguiu confirmar uma identidade"re-construída" - ou José não conseguiu reconhecer nesse grupo tal confirmação em um segundo momento, outro grupo de convívio pôde legitimá-la, de tal forma que José também a reconhecesse como verdadeira, e não fictícia.

O caminho de José foi esse, poderia ter sido outro. Entretanto, sua trajetória nos aponta que, se um grupo social pode ser importante na indução do comportamento aditivo, então ele também poderia contribuir para a indução à sobriedade, o que sugere que não somente José precisava de ajuda, mas também sua familia. Isso ressalta a importância de tratamentos voltados para a recuperação do alcoolista incluírem também as pessoas que com ele são co-dependentes, principalmente os familiares.

Acreditamos que essa história não seja específica desse José, mas se trata de uma história comum a muitos outros "Zés". Assim, a compreensão da dinâmica identitária desse Zé certamente poderá servir a outras áreas do conhecimento voltadas para a dependência química, de tal forma que venham a favorecer a aquisição, pelos co-dependentes envolvidos, de habilidades necessárias para o enfrentamento de um problema crônico na recuperação do alcoolismo: a recaída.

\section{Referências}

Almeida, O. P., Dractu, L., \& Laranjeira, R. (1996). Manual de psiquiatria. Rio de Janeiro: Guanabara Koogan.

Baltieri, D. A. (2004). Tratamento farmacológico do alcoolismo. São Paulo: Lemos.

Beck, A., \&Wright, F. D. (2001). Cognitive therapy of substance abuse. New York: Guilford Press.

Becker, H. S. (1999). Métodos de pesquisas em ciências sociais. São Paulo: Hucitec.

Berger, P., \& Luckmann, T. (1985). A construção social da realidade. Petrópolis: Vozes.

Campos, E. A. (2004). As representações sobre o alcoolismo em uma associação de ex-bebedores: os 'Alcoólicos Anônimos'. Cadernos de Saúde Pública, 20 (5), 1379-1387.

Campos, G. M. (2003). Você tem sede de quê? Um olhar psicossocial na identidade de um alcoolista. Pesquisa de Iniciação Científica não-publicada, Universidade São Marcos, São Paulo.

Carlini, E. A., Galduróz, J. C. F., Noto, A. R., \& Nappo, S. A. (2002). I Levantamento domiciliar sobre uso de drogas psicotrópicas no Brasil: estudo envolvendo as 107 maiores cidades do país - 2001. São Paulo: Secretaria Nacional Antidrogas.

Ciampa, A. C. (1977). A identidade social e suas relações com a ideologia. São Paulo. Dissertação de mestrado nãopublicada, Pontifícia Universidade Católica de São Paulo.

Ciampa, A. C. (1990). A estória do Severino e a história da Severina. São Paulo: Brasiliense, 1990.

Ciampa, A. C. (1994). Identidade. In S. T. M. Lane \& W. Codo (Orgs.), Psicologia Social: o homem em movimento (pp.58-75). São Paulo: Brasiliense.

Dalla-Déa, H. R. F., Santos, É. N., Itakura, E., \& Olic, T. B. (2004). A inserção do psicólogo no trabalho de prevenção ao abuso de álcool e outras drogas. Psicologia: Ciência e Profissão, 24 (1), 108-115.

Duvee, G. (1998). A construção da alteridade. In A. Arruda (Org.), Representando a alteridade. Petrópolis: Vozes.

Edwards, G., \& Dare, C. (1997). Psicoterapia e tratamento das adições. Porto Alegre: Artes Médicas. 
Edwards, G., Marshall, E. J., \& Cook, C. C. H. (1999). O tratamento do alcoolismo: um guia para profissionais da saúde. Porto Alegre: Artes Médicas Sul.

Ferreira, R. F. (2000). Afrodescendente: identidade em construção. São Paulo: EDUC.

Focchi, G. R. A., Leite, M. C., Laranjeira, R., \& Andrade, A. G. (2001). Dependência química: novos modelos de tratamento. São Paulo: Lemos.

Galduróz, J. C. F., \& Caetano, R. (2004). Epidemiologia do uso de álcool no Brasil. Revista Brasileira de Psiquiatria, 26 (Supl. 1), 3-6.

Galduróz, J. C., Noto, A. R., \& Carlini, E. A. (1997). IV levantamento sobre o uso de drogas entre estudantes de 10 e $2^{\circ}$ Graus em 10 capitais brasileiras. São Paulo: CEBRID.

Galduróz, J. C., Noto, A. R., Nappo, S. A., \& Carlini, E. A. (2000). I Levantamento domiciliar nacional sobre uso de drogas psicotrópicas: Parte A - Estudo envolvendo as 24 maiores cidades do Estado de São Paulo - 1999. São Paulo: Centro Brasileiro de Informações sobre Drogas Psicotrópicas, Escola Paulista de Medicina.

Goffman, E. (1963). Estigma: notas sobre a manipulação da identidade deteriorada. Rio de Janeiro: Guanabara Koogan.

Hirata, E. S., Almeida, O. P., Funari, R. R., \& Klein, E. L. (1997). Alcoholism in a geriatric outpatient clinic of São Paulo-Brazil. Int Psychogeriatr, 9 (1), 95-103.

Jodelet, D. (2001). As representações sociais. Rio de Janeiro: Ed. UERJ.

Laranjeira, R., Nicastri, S., Jeronimo, C., \& Marques, A. C. (2000). Consenso sobre a Síndrome de Abstinência do Álcool e o seu tratamento. Revista Brasileira de Psiquiatria, $22(2), 62-71$.

Laranjeira, R., \& Pinsky, I. (2001). O alcoolismo. São Paulo: Contexto.

Laville, C., \& Dionne, J. (1999). A construção do saber: manual de metodologia da pesquisa em Ciências Humanas. Porto Alegre: Artmed.

Marlatt, G. A. (1999). Redução de danos: estratégias práticas para lidar com comportamentos de alto risco. Porto Alegre: Artes Médicas Sul.

Marlatt, G. A., \& Gordon, J. R. (Orgs.). (1993). Prevenção de recaída: estratégias de manutenção no tratamento de comportamentos adictivos. Porto Alegre: Artes Médicas Sul.
Mattos, R. M., Castanho, M. I. S., \& Ferreira, R. F. (2003). Contribuição de Vygostsky ao conceito de identidade: uma leitura da autobiografia de Esmeralda. Estudos e Pesquisas em Psicologia, 3 (1), 119-137.

Micheli, D., \& Formigoni, M. L. O. S. (2001). As razões para o primeiro uso de drogas e as circunstâncias familiares prevêem os padrões de uso futuro? Jornal Brasileiro de Dependências Químicas, 2 (1), 20-30.

Miller W. R., \& Rollnick, S. (2001). Entrevista motivacional: preparando as pessoas para a mudança de comportamentos adictivos. Porto Alegre: Artmed.

Moraes, E., \& Figlie, N. B. (2004). Abuso de álcool, tabaco e outras drogas na adolescência. In N. B. Figlie, S. Bordin \& R. Laranjeira (Orgs.), Aconselhamento em dependência química (pp.321-338). São Paulo: Roca.

Moscovici, S. (2003). Representações sociais. Investigações em psicologia social. Petrópolis: Vozes.

Oliveira, M. K. (1993). Vygotsky: aprendizado e desenvolvimento, um processo histórico. São Paulo: Scipione.

Pechansky, F., Szobot, C. M., \& Scivoletto, S. (2004). Uso de álcool entre adolescentes: conceitos, características epidemiológicas e fatores etiopatogênicos. Revista Brasileira de Psiquiatria, 26 (Supl. 1), 14-17.

Queiroz, M. I. P. (1991). Variações sobre a técnica de gravador no registro da informação viva. São Paulo: T.A. Queiroz.

Ramos, S. P., \& Bertolete, J. M. (1997). O Alcoolismo hoje. Porto Alegre: Artes Médicas.

Rigotto, S. D., \& Gomes, W. B. (2002). Contextos de abstinência e de recaída na recuperação da dependência química. Psicologia: Teoria e Pesquisa, 18 (1), 95-106.

Rodrigues, J. T., \& Almeida, L. P. (2002) Liberdade e compulsão: uma análise da programação dos doze passos dos Alcoólicos Anônimos. Psicologia em Estudo, 7 (1), 113-120.

Silveira Filho, D. X. (1995). Drogas: uma compreensão psicodinâmica das farmacodependências. São Paulo: Casa do Psicólogo.

Vaillant, G. (1999). A história natural do alcoolismo revisitada. Porto Alegre: Artes Médicas.

Recebido em: 26/10/2005

Versão final reapresentada em: 31/3/2006

Aprovado em: 22/5/2006 
